\title{
An Exploration of Business Librarian Participation in Knowledge Synthesis Reviews
}

\author{
Zahra Premji, Ryan Splenda, and Sarah Young
}

Systematic reviews and other forms of knowledge synthesis are increasingly common in the social sciences, including in business and management research. We surveyed academic business librarians to determine the extent of their involvement, in any capacity, in knowledge syntheses. Of 71 eligible responses, 30 percent were involved in supporting knowledge synthesis, while others expressed an awareness of and interest in knowledge synthesis methods and have participated in training opportunities to support these types of projects in the future. While still nascent, knowledge synthesis support by business librarians presents potential as a new service area providing opportunities for deep engagement with faculty research.

\section{Introduction}

The amount of published research has grown tremendously in the past several decades, and the rate of publishing increased significantly with the advent of digital publishing platforms. At the same time, the paradigm of evidence-based policy and decision-making has gained traction across sectors, and so has the need to synthesize evidence and knowledge from research. Systematic approaches to knowledge synthesis have proliferated, beginning with meta-analysis and systematic reviews, which became established in medical research in the 1970s and 1980s, to methods such as realist reviews, meta-narrative reviews, and many others spanning research disciplines. ${ }^{1}$

The discipline of business and management has been somewhat slow to adopt systematic methods of knowledge synthesis. However, a search for meta-analyses and systematic reviews in the business and management subject areas in the Web of Science Core Collection reveals a near 20-fold increase in these types of studies since 2000 (see figure 1). Moreover, the concept of "evidence-based management" has become a topic of study, with the term appearing in the titles or abstracts of nearly 700 published articles in the past five years. ${ }^{2}$ Some recent management literature indicates a growing recognition of the role of knowledge synthesis in the discipline. ${ }^{3}$ Organizations like the Center for Evidence-based Management (CEBMa) ${ }^{4}$ and the Campbell Collaboration ${ }^{5}$ have championed the application of systematic knowledge synthesis methods to inform business and management decision-making. CEBMa has developed methods for critically appraised topics (or CATs) to rapidly gather and assess research evidence. The Campbell Collaboration, an international organization that produces systematic reviews in the

\footnotetext{
*Zahra Premji is Health Research Librarian at University of Victoria in Canada; email: zahrapremji@uvic.ca. Ryan Splenda is Business E Economics Librarian at Carnegie Mellon University; email: rsplenda@andrew.cmu.edu. Sarah Young is Liaison Librarian at Carnegie Mellon University; email: sarahy@andrew.cmu.edu. (C2022, Zahra Premji, Ryan Splenda, and Sarah Young, Attribution-NonCommercial (https://creativecommons.org/licenses/by-nc/4.0/) CC BY-NC
} 
social sciences, formed a Business and Management coordinating group in 2018 to develop and disseminate systematic reviews on topics in this domain as well as guidance and methods for knowledge synthesis. ${ }^{6}$ With the growth of knowledge synthesis research in business and management and new organizations devoted to spreading this methodology, it is important to examine the participation and roles of business librarians in these research efforts.

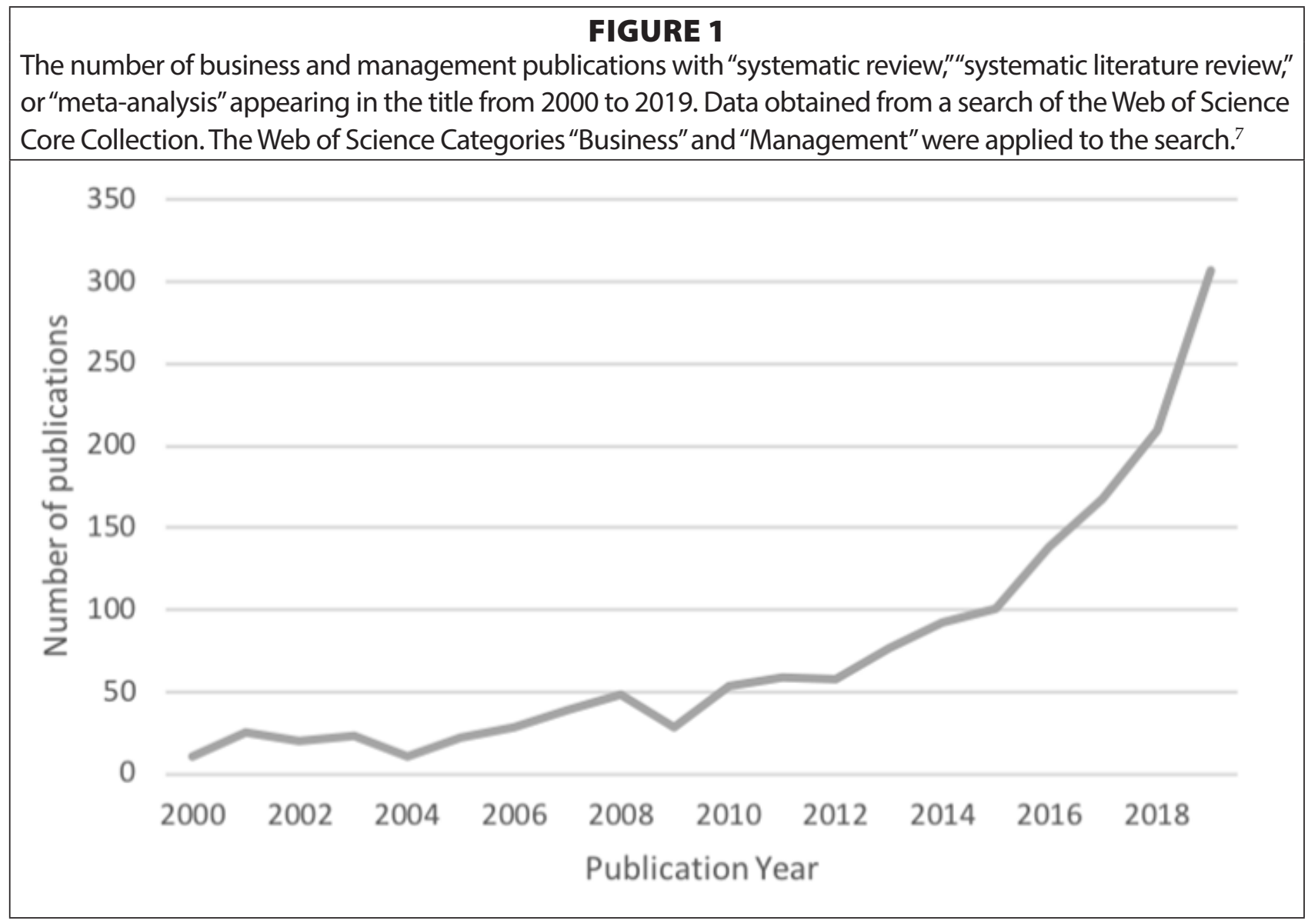

\section{Literature Review}

Despite the diversification of knowledge synthesis methods in recent years, a common element across these methods is a systematic approach to finding relevant studies. This often involves comprehensive searches of bibliographic databases and other sources of information. Moreover, published standards for reporting in systematic reviews and meta-analyses require the transparent and reproducible documentation of searches. ${ }^{8}$ Studies have shown that librarian or information specialist co-authors improve the quality and reproducibility of searches in systematic reviews. ${ }^{9}$ Librarians possess deep knowledge of the information landscape and expertise in database searching and information management. They also assist research teams with question formulation and play key roles in search strategy development. ${ }^{10}$ Increasingly, librarians are also involved as methodological peer reviewers for systematic reviews in disciplines like medicine and the health sciences. ${ }^{11}$ In medicine, where systematic reviews are well established, libraries often provide formalized systematic review services and librarians serve as members of research teams and co-authors on published reviews. These librarians typically have specialized training on systematic review methods, either through formal librarian-focused training programs or through on-the-job mentorship and experience. 
With the increase in knowledge synthesis research outside of medicine, nonmedical librarians may be increasingly called upon to support the development of systematic reviews, scoping reviews, and related types of reviews. Thus, libraries may need to consider building capacity and expertise in these areas, and some nonmedical libraries have already established formal systematic review services. ${ }^{12}$ Some work has been done to benchmark the involvement of librarians in health sciences and veterinary medicine in supporting knowledge synthesis, ${ }^{13}$ but, to date, little research exists on the state of knowledge synthesis in business and management librarianship.

There is some evidence that business librarians are involved in knowledge synthesis research, but there remains uncertainty around the extent of their involvement, to what degree they receive authorship or acknowledgment credit for their contribution, and the level of demand for knowledge synthesis support in business and management libraries. For instance, one study that examined 152 systematic reviews in the areas of organizational psychology, counseling psychology, and management showed that librarian involvement was reported in only one of those systematic reviews $(0.66 \%) .{ }^{14}$ Another study sought to determine the level of librarian involvement in business- and management-related topics and found that only three out of $100(3 \%)$ systematic reviews examined mentioned business librarian involvement. ${ }^{15}$ Some evidence of business librarian involvement in systematic reviews at the individual level has been reported, ${ }^{16}$ but a broader assessment of business librarian involvement in knowledge synthesis is necessary to inform capacity building and service models for business libraries moving forward.

The aim of this study is to fill this gap by establishing a baseline for business librarian involvement in knowledge synthesis. The study's objectives were to assess the following areas: 1) the current knowledge synthesis awareness among business librarians; 2) their involvement in various types of knowledge synthesis; 3 ) the level of training and training formats used to develop competencies; and 4) barriers to participation among librarians supporting academic programs of business and management. This baseline will be valuable for assessing growth in this service area in the future.

\section{Methods}

An online survey (see appendix) was created using Qualtrics software and distributed on April 2, 2020, via the following email lists:

- BUSLIB-L, an unmoderated email discussion list for those interested in business librarianship and information services

- BRASS-L, the email list for the Business Reference and Services Section of the Reference and User Services Association, which is part of the American Library Association

- ABLD-L, the email list for the Academic Business Library Directors group

- Email list for the Special Libraries Association, Business and Finance Division

These were selected as they are four email lists with broad participation among business librarians across the globe.

Business librarians currently working in an academic setting providing services to business-related subject areas were eligible to participate. Academic business librarians who resided in countries subject to the General Data Protection Regulation (GDPR) were not eligible to participate, and this was specifically stated in the recruitment email; this exclusion was a requirement of the institutional review board at the institution of two of the investigators. 
The survey contained 24 questions and included single-answer multiple-choice and multiple-answer multiple-choice, as well as open-text questions. The survey began with an electronic consent form, followed by a question to confirm eligibility to participate in the study. This was followed by six demographic questions including the country of work, years of experience as an academic business librarian, graduate-level degrees held by the respondent, type of institution and level of students served in their current position. A definition of knowledge synthesis from the Canadian Institutes of Health Research was provided to participants at the beginning of the next section of the survey to ensure that participants understood how knowledge synthesis reviews differ from traditional literature reviews. Furthermore, it was explicitly noted that participation in traditional or narrative literature reviews was not under consideration in this study.

The next section of the survey addressed familiarity and participation in knowledge synthesis reviews. This included questions such as the types of reviews in which participants had been involved, their specific role in these reviews, the steps of the review in which they were involved, and how long they had been providing support for knowledge synthesis reviews. This was followed by questions on training and barriers to participation. The question on barriers to participation (question 21 in our survey) was adapted from question 4 of the survey developed by Toews for benchmarking librarians' involvement in systematic reviews in veterinary medicine. ${ }^{17}$ The final three questions were open-text questions to address the challenges, benefits, and successes of review involvement, as well as allowing for additional comments. The survey questions were chosen based on the authors' experiences as well as from the literature review, which included the two benchmarking studies previously mentioned. The survey instrument used split paths, or skip logic, to show only questions that were relevant to the respondent based on responses to previous questions. For example, if a respondent selected "no" to the question on involvement in knowledge synthesis reviews, then they did not see the questions about the review steps in which they had been involved. The survey tool was piloted by two librarians and the feedback was incorporated prior to survey deployment.

The electronic consent form at the beginning of the survey provided participants with information regarding the purpose of the research and the ways in which the data would be shared and disseminated. No incentives were provided for completion of the survey. Data captured from incomplete surveys were not included in the results. No personal identifiable information was collected as part of the survey. The survey was open for six weeks from April 2 to May 15, 2020.

The survey data were exported into a Microsoft Excel file. Data from respondents who completed the survey but were not eligible (for example, those who responded No to question 2) or data from incomplete surveys were removed before analysis. Cross-analysis between various pairs of questions was done in Qualtrics. The text responses were qualitatively analyzed for common themes. Analysis of the text responses was done manually by each of the authors, first independently and then as a group, to identify recurring comments. The dataset containing all eligible survey responses is available and can be downloaded from Dataverse (https://doi.org/10.5683/SP2/JGJXUP).

This research project received ethics approval from the University of Calgary Conjoint Faculties Research Ethics Board and Carnegie Mellon University's Institutional Review Board. 


\section{Results}

A total of 80 responses were collected. After removing the nine ineligible and/or incomplete responses, 71 complete responses were obtained and have been included.

The demographics of the 71 respondents to our survey are shown in table 1 . Almost all respondents were from North America, with one response from China. Respondents were dispersed across years of experience; however, more than 50 percent were mid- to late-career librarians with more than 10 years of experience. More than half of the respondents hold advanced degrees in addition to their MLIS degrees, and the vast majority support both undergraduate and graduate programs.

\section{Familiarity and Participation in Knowledge Synthesis}

Before determining the level of business librarians' involvement in knowledge syntheses, it was first necessary to establish how familiar business librarians are with knowledge synthesis methodology. The majority of respondents were at least somewhat familiar with knowledge synthesis methods $(n=53,75 \%)$, with eight, or 11 percent, indicating deep familiarity with these methods (see figure 2). These data suggest that there is some knowledge synthesis activity in the business and management discipline and that business librarians may be working with their constituents to assist with these efforts. On the other end of the spectrum, 10 respondents $(14 \%)$ indicated a lack of familiarity with this methodology. This is not surprising since systematic reviews, and other types of knowledge synthesis, are still a relatively new concept in the business and management discipline and in business librarianship.

\begin{tabular}{|c|c|c|c|}
\hline \multicolumn{4}{|c|}{$\begin{array}{c}\text { TABLE } 1 \\
\text { Demographics of the Survey Respondents }\end{array}$} \\
\hline Characteristic $(\mathrm{N}=71)$ & & $\mathbf{N}$ & $\%$ \\
\hline \multicolumn{4}{|l|}{ Country of Work } \\
\hline & United States of America & 60 & 84.5 \\
\hline & Canada & 10 & 14.1 \\
\hline & China & 1 & 1.4 \\
\hline \multicolumn{4}{|c|}{ Years of Experience as an Academic Business Librarian } \\
\hline & $0-2$ years & 11 & 15.5 \\
\hline & $3-5$ years & 11 & 15.5 \\
\hline & $6-10$ years & 11 & 15.5 \\
\hline & More than 10 years & 38 & 53.5 \\
\hline \multicolumn{4}{|c|}{ Degrees Held by Respondents } \\
\hline \multirow[t]{2}{*}{ A. Accredited MLIS } & MLIS & 68 & 95.8 \\
\hline & No MLIS & 3 & 4.2 \\
\hline \multirow[t]{3}{*}{ B. Other graduate degrees } & $\mathrm{PhD}$ & 2 & 2.8 \\
\hline & Other Masters & 38 & 53.5 \\
\hline & None & 31 & 43.7 \\
\hline \multicolumn{4}{|c|}{ Degree Programs Served by the Librarian } \\
\hline \multicolumn{2}{|l|}{ Undergraduate only } & 2 & 2.8 \\
\hline \multicolumn{2}{|l|}{ Graduate only } & 6 & 8.5 \\
\hline \multicolumn{2}{|c|}{ Both undergraduate and graduate } & 63 & 88.7 \\
\hline
\end{tabular}






\section{FIGURE 3}

Business and Management Librarian Involvement in Systematic Reviews, Meta-analysis, and Other Knowledge Synthesis Reviews ( $\mathbf{N}=71)$

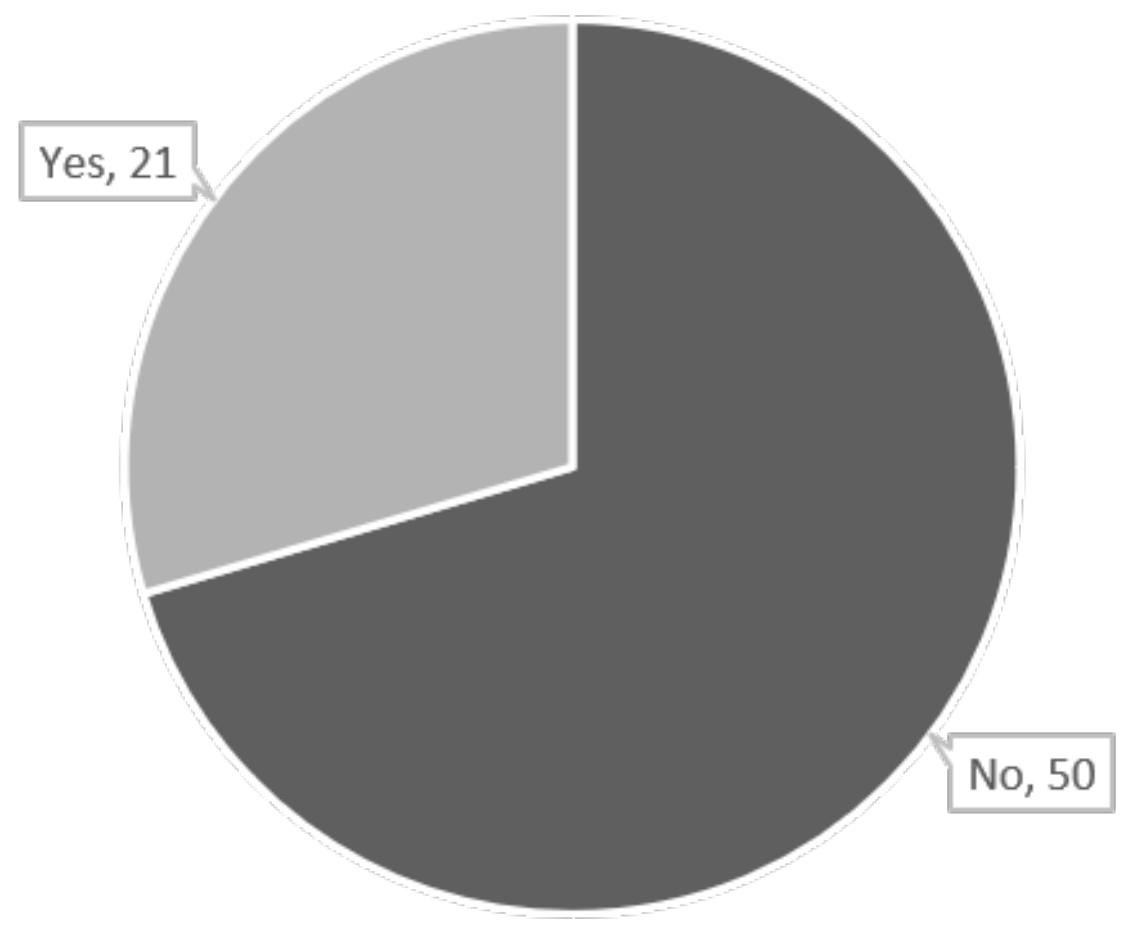


The next step was to determine if business librarians have been or are currently involved in supporting systematic reviews, meta-analyses, or other knowledge synthesis reviews in business and management.

Figure 3 shows that the majority of respondents ( $n=50,70 \%)$ have not been involved in supporting these efforts.

For those respondents indicating some experience with knowledge synthesis, we were interested in determining how long they had been involved in this activity to understand the evolution of this service area.

Seventeen of 21 respondents (81\%) have been supporting knowledge synthesis reviews for five years or less, and 10 of 21 respondents (48\%) have been supporting knowledge synthesis reviews for two years or less (see figure 4). These data suggest that this remains a novel service area in business librarianship, but that it is not a completely new concept within the field. Like many other nonmedical disciplines, knowledge synthesis methodology is starting to gain traction in business and management, but the data clearly suggest that it is in its nascent stages with potential for growth, and thus a need for training opportunities, for business librarians.

\section{Librarian Roles in Knowledge Synthesis}

Of the respondents who indicated that they provided some knowledge synthesis support $(\mathrm{N}=21)$, the majority $(\mathrm{n}=16,76 \%)$ indicated involvement in systematic reviews specifically. Eleven respondents (52\%) also provided support for meta-analyses, and seven respondents (33\%) provided support for other types of knowledge synthesis reviews (for example, scoping reviews, realist reviews, and others). Like library services for knowledge synthesis in many

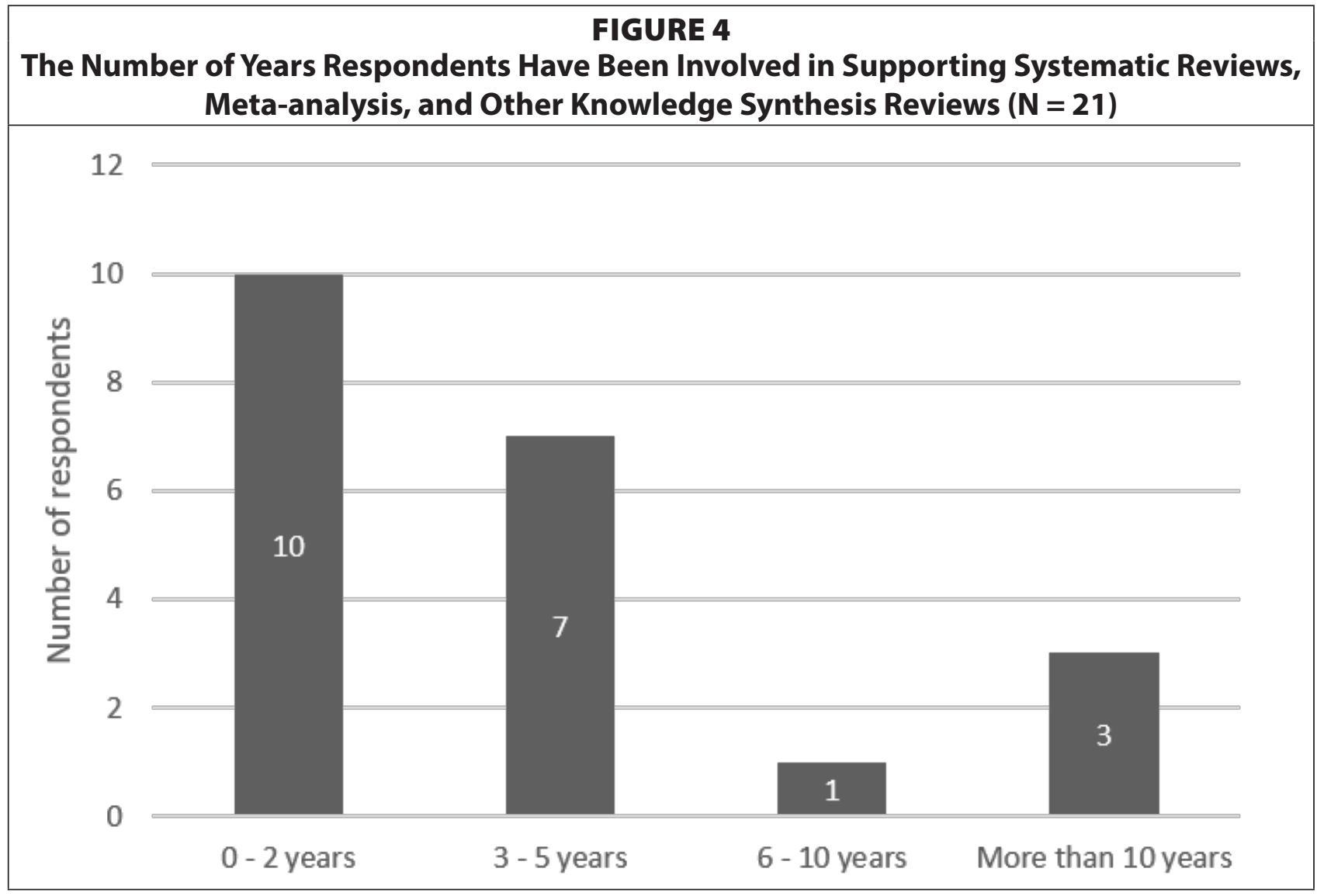


other nonmedical disciplines, services for business and management are starting to gain traction, and the data show that there is some movement in business librarianship toward supporting or collaborating on this type of research. Given that knowledge synthesis tends to be a more advanced research method, it is important to note the populations that business librarians support in these efforts. Of the 20 respondents who answered this question, the vast majority support knowledge synthesis research at the faculty $(n=16,80 \%)$ and graduate levels $(n=13,65 \%)$. Knowledge synthesis support for postdoctoral researchers $(n=4,20 \%)$ and undergraduates $(n=3,15 \%)$ is much less common, with the least commonly supported group being external or professional organizations $(n=2,10 \%)$. Nevertheless, many librarians work with multiple academic user groups.

Of the respondents that indicated experience with supporting knowledge synthesis, most do so in a consulting role. We were interested in understanding those steps in the knowledge synthesis process in which business librarians have been involved. Of the 19 respondents who stated they were involved in knowledge synthesis reviews in a consulting role, the vast majority of them provide support in the earlier stages of the knowledge synthesis process. These include choosing information sources $(\mathrm{N}=19,100 \%)$, designing the search $(\mathrm{n}=14,74 \%)$, and question formulation ( $\mathrm{n}=12,63 \%$ ) (see figure 5). This comes as no surprise as these are the steps most commonly supported by librarians. ${ }^{18}$

It is interesting to note that some respondents provide support in the later stages of knowledge synthesis. Most notably, two business librarians (11\% of all respondents) provided support at the study selection (screening), critical appraisal, and reporting (PRISMA) or manuscript preparation stages. This again suggests that, although at a very small percentage, there is advanced systematic review work being done by business librarians in the business and management discipline, and this is indeed not a new practice or concept within the field. For those who are interested in promoting and expanding this methodology in the field, these data come as welcome news.

One area for improvement for business librarians is recognition as a co-author on the final published knowledge synthesis. Only three of the 21 respondents $(14 \%)$ indicated

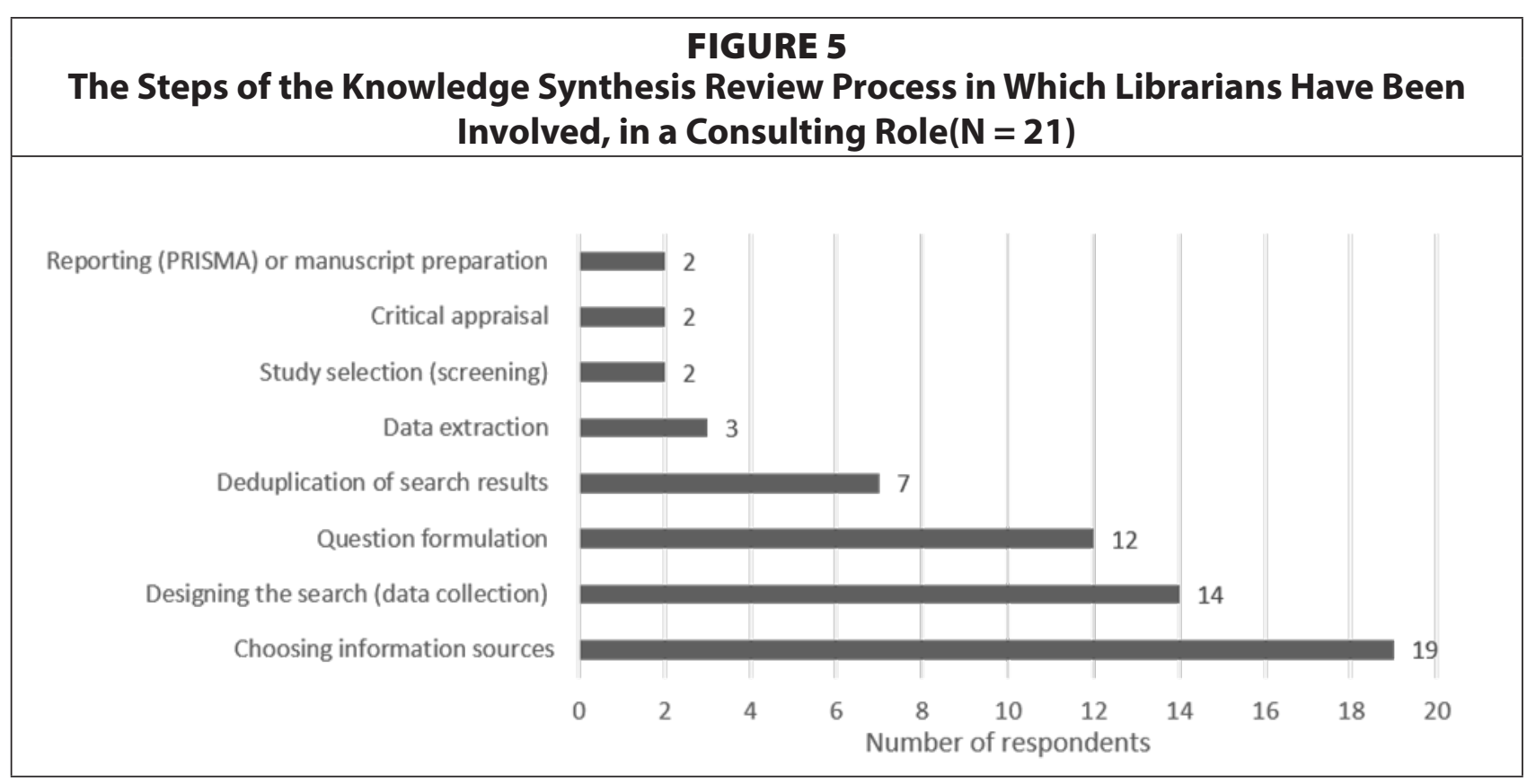


that they have received co-author status, of which one indicated they were a co-author on a systematic review, one was a co-author on a meta-analysis, and one was a co-author on another type of knowledge synthesis project. Furthermore, we asked the respondents if they had been formally acknowledged in the final knowledge synthesis manuscripts. Only three of the 20 respondents $(15 \%)$ indicated that they were sometimes acknowledged in the final manuscript. Eleven respondents (55\%) did not know if they had been acknowledged and six respondents (30\%) indicated that they were never acknowledged. Much like the argument for advocating for co-author status, it is also reasonable for business librarians to push for acknowledgment in final manuscripts when their involvement is time consuming, makes a significant intellectual contribution, and requires a significant level of expertise.

Of the three respondents who had co-authored knowledge syntheses, two provided support in every step of the process [question formation, choosing information sources, designing the search (data collection), deduplication of search results, study selection (screening), data extraction, critical appraisal, and reporting (PRISMA) or manuscript preparation]. All three of the respondents provided support in the following steps: choosing information sources, designing the search (data collection), deduplication of search results, study selection (screening), and data extraction. It is interesting that all three respondents provided support in the majority of the steps of the knowledge synthesis process, thus indicating a level of involvement worthy of co-authorship credit.

\section{Training and Development}

Training is an important aspect of supporting knowledge synthesis reviews. Training can take the form of formal courses; these occur both in person (such as the training courses offered by evidence synthesis organizations or credit-bearing courses offered at higher education institutions) as well as online (such as MOOCs or learning modules offered by evidence synthesis organizations). They can also take the form of in-person workshops (single or multisession), such as those offered by many academic libraries, webinars, and other online training options such as webinars hosted by academic librarians, library associations, or evidence synthesis organizations such as Cochrane and the Campbell Collaboration. Additional formats of training could include self-directed reading, engaging in a community of practice, or on-the-job training such as shadowing or mentorship by an experienced librarian or academic. We also wanted to assess whether additional benefits exist from formalized modes of training versus the more informal formats of training. Thus, for the purpose of the analysis, we grouped the question choices into two categories: formal (F) and informal (I) training formats. Formal training can be considered training occurring in a classroom setting (teacher and student) be it physically or virtually. Based on this definition, we grouped the systematic review course, in-person workshops, and webinars together as formal training formats and considered the remaining options (selfdirected reading, community of practice, and on-the-job training by other librarians) as informal formats of training.

We asked respondents whether they had participated in training on knowledge synthesis methods. Nineteen respondents (of the 71) had training. For those who responded "yes" to having had training, we asked about the type of training and what had prompted their training. The responses to these questions can be found in table 2 . 


\begin{tabular}{|c|c|c|}
\hline \multicolumn{3}{|c|}{$\begin{array}{l}\text { TABLE } 2 \\
\text { Participation in Training, Formats of Training, and Motivations for Training }\end{array}$} \\
\hline Characteristic & $\mathbf{N}$ & $\%$ \\
\hline \multicolumn{3}{|l|}{ Participated in Knowledge Synthesis Training ( $\mathbf{N}=71)$} \\
\hline Yes & 19 & 26.7 \\
\hline No & 52 & 73.2 \\
\hline \multicolumn{3}{|l|}{ Training Format (I = Informal, F = Formal) $(\mathrm{N}=19)$} \\
\hline Self-directed reading (I) & 12 & 63.2 \\
\hline On-the-job training by other librarians (I) & 10 & 52.6 \\
\hline Workshops (in-person) (F) & 7 & 36.8 \\
\hline Webinars or online training $(F)$ & 4 & 21.1 \\
\hline Systematic review course (F) & 4 & 21.1 \\
\hline Community of practice (1) & 2 & 10.5 \\
\hline \multicolumn{3}{|l|}{ Number of Different Training Formats Selected by Respondents $(N=19)$} \\
\hline 1 & 6 & 31.6 \\
\hline 2 & 7 & 36.8 \\
\hline 3 & 5 & 26.3 \\
\hline 5 & 1 & 5.3 \\
\hline \multicolumn{3}{|l|}{ What Prompted Your Training } \\
\hline Required for current job/role & 1 & \\
\hline Required for previous job/role & 1 & \\
\hline Interest in developing this as a service/role & 14 & \\
\hline Personal or professional interest (but not a requirement of my job) & 13 & \\
\hline Other & 3 & \\
\hline \multicolumn{3}{|l|}{ Formal Versus Informal Training (grouped) $(\mathrm{N}=19)$} \\
\hline At least one formal training type & 11 & 57.0 \\
\hline At least one informal training type & 19 & 100 \\
\hline
\end{tabular}

The two most common reasons for participating in training were: interest in developing this as a service $(\mathrm{N}=14)$ and personal or professional interest, but not a requirement of my job $(\mathrm{N}=13)$. Surprisingly, only one respondent said that the training was prompted by either a current job or previous job, respectively. This highlights business librarians' interest in developing further in this area and potentially offering related services in the future.

It is interesting to note that every respondent who had training reported at least one informal training format $(\mathrm{N}=19)$, but only 11 respondents reported at least one of the formal training formats. This means that eight of the respondents have only had informal formats of training.

When selecting the format of training, many respondents chose more than one option. Of the 19 respondents who reported that they participated in training, six engaged in only one type, and that training was informal. Seven respondents engaged in two types, five in three types and one respondent engaged in five types. Respondents seemed to recognize the need for training. We asked respondents about what had limited their ability to participate in knowledge synthesis reviews. Thirty respondents selected "I don't have sufficient train- 
ing" as an option. Of the 30 respondents who chose this option, five respondents currently participate in supporting reviews and 25 respondents do not currently participate in supporting knowledge synthesis reviews. Further evidence was found in the free-text responses. Respondents mentioned they would like advanced training, that they lacked advanced-level knowledge and skills or training and support or would like additional training applicable to business librarianship.

\section{Barriers, Benefits, and Challenges}

Respondents indicated a variety of reasons for a lack of involvement in knowledge synthesis (see figure 6). However, overwhelmingly respondents noted that they had received few requests $(\mathrm{N}=60,88 \%)$ and that faculty and students at their institution rarely conduct systematic or knowledge synthesis reviews $(\mathrm{N}=36,53 \%)$. Of the six respondents $(\mathrm{N}=6,9 \%)$ who did not note a lack of interest or need among their constituents, three reported a lack of training and three reported a lack of time, with one respondent reporting both a lack of training and a lack of time as the main barriers to involvement in knowledge syntheses. One respondent reported that knowledge synthesis was not part of their assigned duties as the only reason $(\mathrm{N}=1)$.

The apparent lack of need experienced by many of the respondents was also indicated in their answers to the free-text questions. Here are a few key observations:

- "I've received no request for these types of reviews from our School of Business, which, by the way, has AACSB accreditation."

- "This has not caught on yet in the business college at my university, but I am monitoring the situation to see if it does."

- "Systematic reviews are geared towards health sciences; business research rarely needs SRs except health management research."

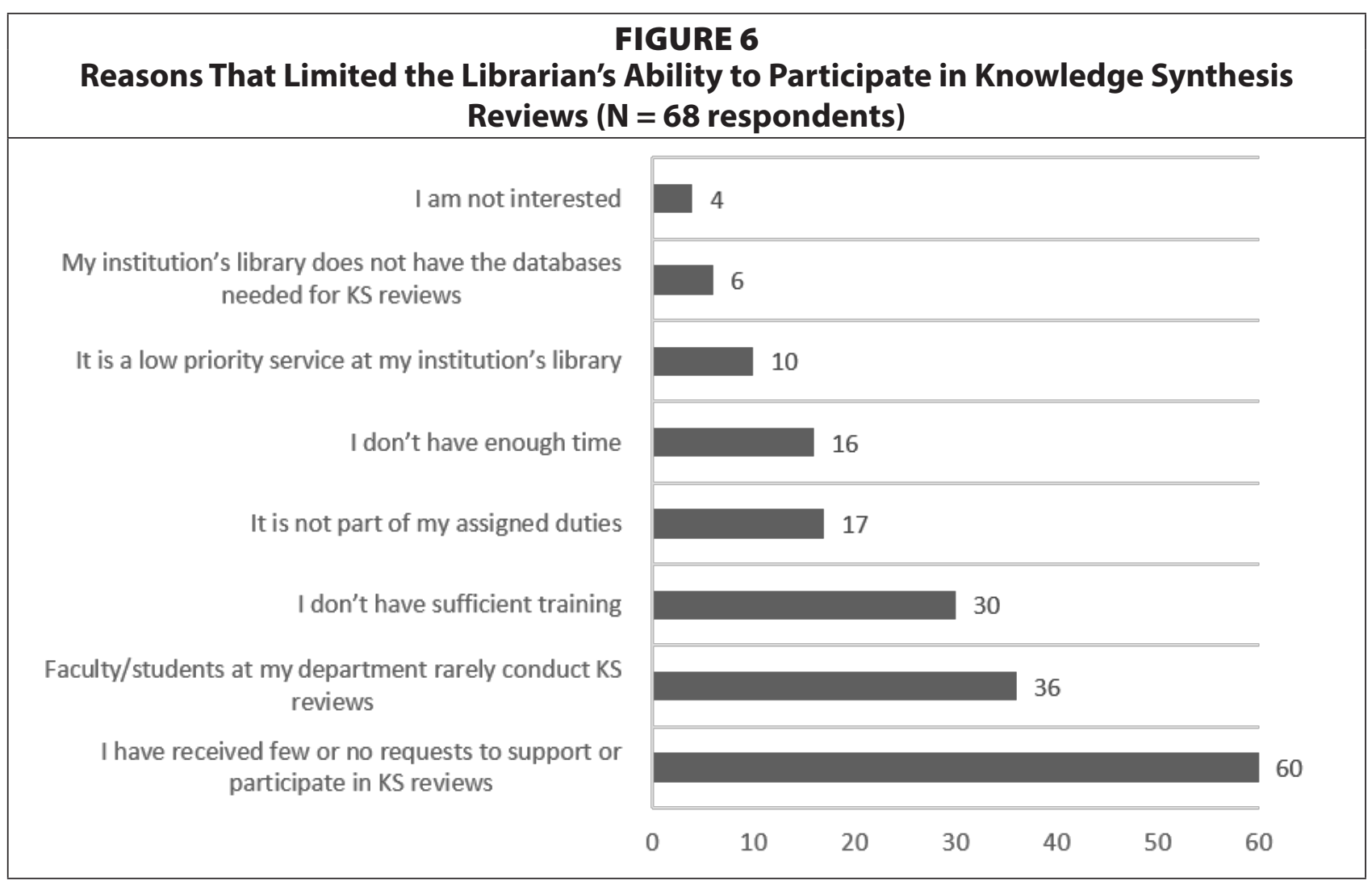


When asked about the benefits of getting involved in knowledge synthesis reviews, responses included the following: Deeper, meaningful engagement with faculty and students; Strengthen relationships; Opportunity to learn more about the research and resources; Informs graduate and faculty consultations; Ability to provide services demonstrates value; Exciting or interesting; and Getting to use in-depth searching skills (librarian skills). Of particular note, one respondent indicated, "The dean of our College of Business has expressed a desire for the libraries to potentially help with this service."

\section{Discussion}

Librarians are known to play a critical role in the production of high-quality knowledge synthesis. Several studies in various domains have been carried out to assess librarian awareness and involvement in knowled ge synthesis reviews. For example, similar cross-sectional studies on the participation of health sciences librarians ${ }^{19}$ and veterinary librarians ${ }^{20}$ in systematic reviews have been reported. To assess the different roles of librarians in knowledge synthesis, these two studies used a list of roles derived from Beverley, Booth, and Bath, ${ }^{21}$ and we used a somewhat modified version of this list to assess the role of business librarians. In the study on health sciences librarians, the three roles most common for librarians in the capacity of an advisor were search strategy developer, database selector, and research question formulator. $^{22}$ Toews' study on veterinary librarians showed the same three roles as the most common when providing research assistance (similar to a consulting role in our survey), but the most common role was database selector, followed by search strategy developer and question formulator. ${ }^{23}$ A study by Bullers et al. ${ }^{24}$ also found that one of the primary roles of librarians are as expert searchers. Expert searching includes tasks such as formulating research questions, selecting appropriate databases, and developing search strategies. Our data show that business librarians, like their veterinary and health sciences counterparts, are involved most commonly in choosing information sources, designing the search, and question formulation, when in a consulting role.

The systematic review methodology is a very long and complex process. Several of the steps in which librarians are traditionally involved are crucial to the success of the project. These steps also take a substantial amount of time, effort, and expertise to complete in a comprehensive and transparent manner. ${ }^{25}$ Most evidence-based organizations like the Cochrane Organization and the Campbell Collaboration heavily encourage the participation and inclusion of librarians on systematic review teams. ${ }^{26}$ In terms of participation as a co-author or team member, Murphy and Boden's study showed that more than 75 percent of librarians reported participating in the top three roles as a team member. ${ }^{27}$ Toews $^{28}$ reported that only half of the veterinary librarians who completed the survey reported participating in the most common roles as a review team member. In contrast, only three of 21 business librarians $(14 \%)$ who reported participating in knowledge synthesis reviews participated as a team member. Librarian co-authors on business/management knowledge synthesis reviews are still rare; however, this may change going forward as researchers become more aware of the information retrieval and methodological expertise business librarians can contribute, and as more business librarians attend training sessions and begin outreach activities as part of developing a service in this area.

Our survey indicated that the majority of business librarians (11 out of 20,55\%) did not know if they had received an acknowledgement for their efforts. A study that reviewed 100 
business-related systematic reviews showed that librarians were mentioned, either in the methods section or the acknowledgments section, in only three of the 100 reviews. ${ }^{29}$ These data suggest that business librarians may not be having this conversation with the researchers they assist, and this is an opportunity to do so. It is certainly reasonable for business librarians to advocate for co-authorship or acknowledgment on the final published reviews to receive credit for their role in the success of the project. This is rare at present, but increased efforts to participate in this methodology by business librarians and the recognition and understanding by researchers that business librarians have a lot to contribute in these efforts could lead to an increase in acknowledgments on final knowledge synthesis reviews. This question was included in our survey but was not asked in either Toews or Murphy and Boden's surveys; therefore, a direct comparison to these other population groups do not exist. However, a survey of library directors ${ }^{30}$ of health sciences libraries showed that librarians were acknowledged or listed as co-authors some of the time (14\%), most of the time (50\%), or all of the time (36\%). As previously discussed, the role of health sciences librarians in knowledge synthesis is much more established. Further, these results include both roles, as a co-author and a consultant; therefore, it is not surprising that these results are significantly higher than what our survey reported.

Business librarians creating their own policies related to librarian involvement in knowledge syntheses can look to academic health sciences libraries, which often define what levels of involvement should translate to acknowledgment or co-authorship. An example of this is Cornell University Library's Evidence Synthesis Service breakdown between librarians as consultants and co-authors when collaborating on an evidence synthesis project. ${ }^{31}$

Systematic reviews and other knowledge synthesis reviews have complex methodologies, and therefore training is a critical component to ensure that librarians have the competencies necessary to adequately support these types of projects. ${ }^{32}$ Our survey data showed that librarians participated in multiple different formats of training, showing that a multipronged training approach seems necessary to develop comfort and competency. There is a role for both formal and informal types of training when developing knowledge of these types of methodologies. One can argue that a mix of both would be ideal. Formalized forms of training can provide a foundation of knowledge and help in gaining an understanding of the intricacies and conceptual underpinnings of the method. Informal training such as on-the-job training, self-directed reading and communities of practice can build upon the foundational knowledge and provide training on the more practical aspects as well as experiential learning opportunities. Furthermore, as databases change, and standards and guidelines surrounding the different knowledge synthesis methods evolve, librarians will need to continue training to remain current. This matches the approaches that some libraries are taking; for example, University of Minnesota, when developing their capacity to support systematic reviews beyond the health sciences, incorporated a two-day training workshop, five expert search camp sessions, as well as ongoing peer support for those librarians who were new to systematic reviews in the form of an apprentice model..$^{33}$

Formal modes of librarian training for knowledge synthesis methods outside of the medical sciences is rare. However, a recent joint effort among knowledge synthesis librarians at Cornell University, the University of Minnesota, and Carnegie Mellon University has produced a workshop series entitled "Systematic Reviews and Evidence Synthesis beyond the Health Sciences: A Training for Librarians." This team was recently awarded a grant from 
the Institute of Museum and Library Services to carry out this training twice yearly during the next three years. ${ }^{34}$

Our survey did not attempt to discover the specific roles/steps of the review for which librarians had sought training. Murphy and Boden ${ }^{35}$ and Toews ${ }^{36}$ asked respondents to selfreport the roles for which they had received training or where they felt they had adequate training (roles previously mentioned include question formulation, database selection, search strategy development, reference management, article selection, data extraction, appraisal of studies, synthesis of results, writing/reviewing of report, and project management). Our survey focused on the formats of training taken by business librarians as part of their overall training in this area. It is interesting to note that business-specific training is rare or nonexistent since the field is relatively new in business librarianship. Therefore, it was anticipated that the informal types of training were likely to be more common. Business librarians, when attempting to determine training needs, might consider consulting an appropriate competency framework geared toward librarians involved in knowledge synthesis reviews. ${ }^{37}$ This is because supporting systematic reviews and other types of knowledge synthesis reviews requires more than just knowledge of information systems and advanced searching. It also requires competencies in the areas of data management, reporting, process or project management, and so on.

Business librarians reported similar barriers to participation in knowledge synthesis as veterinary librarians, ${ }^{38}$ with "few or no requests to conduct or support knowledge synthesis reviews" being the most common barrier, followed by "faculty at my institution rarely conduct knowledge synthesis reviews," which was the second-greatest barrier in our survey and the third in Toews' survey. ${ }^{39}$ However, despite this apparent lack of demand, we know that the number of knowledge syntheses in business and management has seen a dramatic rise in recent years (see figure 1), which is likely to continue. If librarians are well-trained in these methods and poised to support this growing trend, they could help to mitigate the publishing of poor-quality and redundant knowledge syntheses, a problem well noted by Ioannidis ${ }^{40}$ in the field of health and medicine.

The next most common barrier in our survey as well as in Toews' survey was lack of training. The health sciences librarians survey reported a lack of time as the most frequent barrier, followed by a lack of training as the second most common barrier to participation. This lack of training could indicate a lack of training availability or a lack of support or resources available to engage in training opportunities. Finally, the second most common barrier in Toews' survey, which was "library has no policy for librarian role in SRs," was not included as an option in our survey.

There are a lot of similarities between what was reported in Toews and our findings. Because systematic reviews are growing in popularity in veterinary medicine and in business and related disciplines, librarian involvement in these reviews in both subjects is also growing. Furthermore, unlike the health sciences, which have evidence synthesis organizations that publish guidelines and best practices for conducting knowledge synthesis reviews and recommend the involvement of librarians, ${ }^{41}$ veterinary medicine and business as disciplines are still developing in terms of disciplinary guidelines published by relevant evidence synthesis organizations working in these disciplinary areas. With the creation of the Business and Management coordinating group of The Campbell Collaboration in 2018, it is possible that updated guidance that is specific to knowledge synthesis in business may be forthcoming in the future; this may stimulate interest from faculty in conducting knowledge synthesis 
reviews. If this guidance recommends the involvement of business librarians on these projects, then the demand for librarian involvement will also see a rise.

Like many other disciplines where knowledge synthesis reviews are growing in popularity, business is seeing a surge in the number of reviews published. Similarly, involvement from business librarians in systematic reviews and other types of knowledge synthesis reviews is being reported..$^{42}$ Nearly half of the respondents who do participate in knowledge synthesis reviews have only done so for two years or less. Additionally, the most common reason for participating in training related to knowledge synthesis methods was interest in developing this as a service. Business librarians, in keeping up with current trends, are anticipating an increased interest in services related to knowledge synthesis from business researchers. With an increased focus on transparency, reproducibility, and completeness of reporting, librarians are well positioned to take on the role of either consultant (advisor) or team member (co-author), if sufficiently trained in knowledge synthesis methods.

\section{Limitations and Recommendations}

\section{Limitations}

We recognize that there are a number of limitations to our findings. First, GDPR countries were excluded from participation in this study, and 70 of 71 respondents were from North America. Thus, the data represents the North American landscape. In addition, cross-sectional studies suffer from low participation rates. The number of business librarians across North America was not determined; therefore, it is not possible to determine a true response rate for our survey. Because the surveys were distributed via email lists, which are voluntary to join, we cannot claim to have reached all eligible librarians. It is possible that our survey included a positive bias; librarians familiar with knowledge synthesis may have been more likely to respond to this survey. Finally, given that knowledge synthesis is still an emerging area in business and among business librarians, it is possible that respondents may interpret the concept of knowledge synthesis inconsistently when reporting involvement or lack thereof.

\section{Recommendations}

Business librarians recognized the need for training in methods for library support of knowledge synthesis, in anticipation of offering a future service. Business-specific formal training is rare or nonexistent. Nevertheless, opportunities for librarian training in knowledge synthesis for social sciences are becoming available (for example, see the Evidence Synthesis Institute for librarians outside of the health sciences, recently funded by the Institute for Library and Museum Sciences ${ }^{43}$ ). We therefore recommend that business librarians attend training, whether formal or informal, even if they are taught from a different disciplinary perspective. There are commonalities among knowledge synthesis methods across all disciplines; therefore, these training opportunities still have value. Furthermore, knowledge synthesis reviews can cross disciplinary lines. Thus, having an understanding of knowledge synthesis methodologies and how implementation differs across disciplines can be valuable for supporting multidisciplinary knowledge synthesis reviews. Informal training such as communities of practice, peer mentoring, or on-the-job training can be more discipline-specific; we encourage business librarians who are very familiar or have experience with knowledge synthesis support in business to take the lead or contribute to peer-led initiatives to build competencies and capacity in this area. We would also urge associations and special interest groups relevant to business 
librarianship or business reference (such as RUSA's Business Reference and Services Section, and Academic Business Library Directors group) to organize and initiate training, especially business-specific knowledge synthesis training.

While the findings of this survey are limited to business librarians, other social sciences librarians may be in similar stages of growth and developing services and capacity to support knowledge synthesis reviews as they emerge or grow within their respective disciplines. Despite disciplinary nuances, social sciences librarians, life/health sciences librarians new to knowledge synthesis, and business librarians can come together to create communities of practice or peer mentorship programs to support the mutual growth of librarian competencies in this area, as well as to evolve their knowledge of how knowledge synthesis methodology is implemented in other disciplines.

Involvement in knowledge synthesis has already been demonstrated to be of value in the health sciences disciplines and in evidence-based medicine. It is possible that involvement of business librarians in knowledge synthesis may return similar benefits and value propositions for evidence-based management. Business librarians may want to look at peers in the health sciences to identify how they have demonstrated the value of their contributions and to consider similar approaches. This could include formalizing a service model, developing clear policies on the types of support librarians can provide, and creating policies for receiving credit (in terms of acknowledgments or co-authorship) for their contributions. Additionally, librarians should consider a needs assessment to uncover local, contextual needs; this may provide an idea of the initial interest level or demand and can also serve to market the role of the librarians in supporting evidence synthesis to researchers. Business librarians could also consider undertaking research on the current state of methodological rigor and adherence to published guidelines and standards of published knowledge synthesis reviews in business and related disciplines.

\section{Conclusions}

With the growth of systematic reviews and other knowledge synthesis reviews in the area of business and management and the spread of this methodology in various subdisciplines of librarianship, we were interested in examining the current state of business librarians' involvement in this area, which will help to establish a baseline. Our results indicate that there is some business librarian involvement in this methodology, but there is room for additional growth. Likewise, our results indicate that there is a need for additional formal and informal training in this methodology and a more vocal push for either acknowledgment or co-author status in the final manuscript depending on the level of support/collaboration. The overarching benefit for business librarians (and librarians in general) in participating and offering support in knowledge synthesis methodology is an increase in partnerships and collaborations with faculty, students, and researchers. This allows business librarians to partner with their constituents in a different way and can produce deeper and stronger relationships with their faculty and students that also helps raise the profile of the library on campus.

\section{Acknowledgments}

We would like to sincerely thank Dr. K. Alix Hayden and Dr. Justine Wheeler (both from Libraries \& Cultural Resources, University of Calgary) for their assistance with piloting the survey instrument and providing us with constructive feedback that helped improve the clarity, flow, and quality of our survey. 


\section{APPENDIX Survey Instrument}

\section{Q1 Electronic Consent form}

Thank you for taking the time to complete this survey. The data collected in this survey is part of a research project on benchmarking the participation of academic business librarians in supporting or conducting knowledge synthesis research. This study is being conducted by librarians at the University of Calgary and Carnegie Mellon University. This survey should take approximately 7-10 minutes to complete.

\section{Who is eligible to participate?}

You are eligible to participate in this study if you are an academic librarian with liaison responsibilities to a business-related program at any level. You must be at least 18 years of age to participate. If you reside in a country subject to the General Data Protection Regulation (GDPR), you cannot participate in this study.

\section{What type of personal information will be collected?}

No personal identifying information will be collected in this study. We will be collecting some general demographic data including: country, type of institution, years of experience, level of education, and types of students.

\section{What are the risks and benefits of participation?}

Participation in this study is voluntary. As participation is anonymous, there is no way to withdraw from the study once you have submitted your data. You can, however, discontinue the survey at any time before submitting the survey and no data will be retained. There are no known risks of participating in this survey. There are also no direct benefits to any individual from participation in this research.

\section{Compensation}

You will not be compensated for your participation in this study.

\section{What happens to the information in the survey?}

The results of this survey will be published in a conference presentation and/or a journal article. The anonymous data collected will be stored in a data repository and accessible to other researchers.

Questions/Concerns: If you have any questions about this research, please contact any of the investigators, Zahra Premji (email: zahra.premji@ucalgary.ca), Ryan Splenda (email: rsplenda@ andrew.cmu.edu), or Sarah Young (email: sarahy@andrew.cmu.edu).

For any questions related to the ethics for this study, please contact either the University of Calgary Conjoint Faculties Research Ethics Board (CFREB) at cfreb@ucalgary.ca or the Carnegie Mellon University Institutional Review Board at irb-review@andrew.cmu.edu.

If you consent to participate in this study, please select the first option below 
- By selecting this option, I confirm that I am at least 18 , that I have read the information provided above, and that I wish to participate in the research and begin the survey.

$\square \quad$ I do not consent to participating in this survey.

Q2 Are you currently working as an academic librarian in a business-related subject area?

$\square$ Yes

$\square$ No

Q3 What country do you work in?

Q4 Your institution offers business/management programs at the following levels: (Select all that apply)

$\square$ Undergraduate

Master's

口 Doctoral

$\square$ Other, please specify

Q5 How many years of experience do you have as an academic business librarian?

$\square \quad 0-2$ years

$3-5$ years

6-10 years

$\square \quad$ More than 10 years

Q6 Do you have an accredited master's degree in library or information science?

口 Yes

$\square$ No

Q7 Do you have any additional graduate-level degrees in addition to your MLS/MLIS/MIS? (Select all that apply)

Master's-level degree

$\square$ Doctoral-level degree

$\square$ Other, please specify

Q8 What level of students do you work with? (Select all that apply)

$\square \quad$ Undergraduate students

- Master's students

口 Doctoral students

Q9 Knowledge synthesis (KS) is defined as, "the contextualization and integration of research findings of individual research studies within the larger body of knowledge on the topic. A synthesis must be reproducible and transparent in its methods, using quantitative and/ or qualitative methods. It could take the form of a systematic review“ (CIHR, n.d.). Forms of knowledge synthesis that are common in business research are systematic reviews (also called systematic literature review) and meta-analyses. For the purposes of this survey, we 
are excluding traditional or narrative literature reviews as they do not typically follow any particular methodology, whereas knowledge synthesis reviews are expected to follow methodological guidelines. Therefore, when responding to the questions in the rest of the survey, please disregard any support/involvement you have with traditional or narrative literature reviews.

Q10 How familiar are you with systematic reviews, meta-analysis, or other knowledge synthesis reviews?

$\square \quad$ Not at all familiar

$\square$ Somewhat familiar

$\square$ Very familiar

Q11 In your role as a Business Librarian, have you been involved in supporting systematic reviews/meta-analyses/other knowledge synthesis reviews in business/management?

$\square$ Yes

$\square \quad \mathrm{No}$

Q12 In what capacity were you involved in each of these types of knowledge synthesis reviews? (Select all that apply)

\begin{tabular}{|l|l|l|l|}
\hline & $\begin{array}{c}\text { Consulted or } \\
\text { provided support }\end{array}$ & $\begin{array}{c}\text { Involved as a } \\
\text { co-author }\end{array}$ & Not involved \\
\hline Systematic reviews & & & \\
\hline Meta-analyses & & & \\
\hline $\begin{array}{l}\text { Other knowledge synthesis reviews such as scoping } \\
\text { reviews, realist reviews, and the like }\end{array}$ & & & \\
\hline
\end{tabular}

Q13 In a consulting/support role, for which steps of the knowledge synthesis project were you involved in providing support?

$\square$ Question formulation

$\square$ Choosing information sources

$\square$ Designing the search (data collection)

$\square$ Deduplication of search results

$\square \quad$ Study selection (screening)

$\square$ Data extraction

$\square$ Critical appraisal

$\square$ Reporting (PRISMA) or manuscript preparation

$\square$ Other, please elaborate

Q14 In a co-author role, which steps of the knowledge synthesis project were you directly involved in or responsible for?

$\square$ Question formulation

$\square \quad$ Choosing information sources

$\square$ Designing the search (data collection)

$\square$ Deduplication of search results

$\square$ Study selection (screening) 
$\square$ Data extraction

$\square$ Critical appraisal

$\square$ Reporting (PRISMA) or manuscript preparation

$\square$ Other, please elaborate

Q15 How long have you been involved in supporting/co-authoring business/management systematic reviews/meta-analyses/knowledge synthesis reviews?

$\square \quad 0-2$ years

$3-5$ years

6-10 years

$\square$ More than 10 years

Q16 For whom were you providing support? (Select all that apply)

$\square$ Undergraduate students

Graduate students

口 Postdocs

$\square$ Faculty

External/professional organizations

Q17 When involved in a consulting/support role on systematic reviews/meta-analyses, have you been acknowledged in the final manuscript?
$\square$ Always
$\square$ Sometimes
$\square \quad$ Never
口 Not sure

Q18 Have you ever received training (formal, informal, or self-directed) on knowledge synthesis methods such as systematic reviews, meta-analysis, or other review types?

$\square$ Yes

$\square$ No

Q19 In what format was your training on knowledge synthesis methodology? (Select all that apply)

Systematic review course

$\square$ Workshops (in-person)

․ Webinars or online training

$\square$ Self-directed reading

$\square$ Community of practice

$\square$ On-the-job training by other librarians

$\square$ Other, please elaborate

Q20 What prompted your training? (Select all that apply)

$\square$ Required for current job/role

$\square$ Required for previous job/role

$\square$ Interest in developing this as a service/role 
$\square \quad$ Personal or professional interest (but not a requirement of my job)

$\square \quad$ Other, please elaborate

Q21 Which, if any, of the following have limited your ability to participate in any role in systematic reviews, meta-analysis, or other knowledge synthesis reviews? (Please select all that apply).

$\square \quad$ I have received few or no requests to support or participate in systematic/knowledge synthesis reviews

$\square$ Faculty/students at my department rarely conduct systematic/KS reviews

$\square \quad$ I don't have sufficient training

$\square \quad$ It is not part of my assigned duties

$\square \quad$ I don't have enough time

$\square \quad$ It is a low-priority service at my institution's library

$\square$ My institution's library does not have the databases needed for systematic/KS reviews

$\square \quad$ I am not interested

$\square$ Other. Please elaborate

Q22 What challenges have you encountered during your participation in any role on a systematic review, meta-analysis, or other knowledge synthesis review?

Q23 What benefits or successes have you experienced from your participation in any role on a systematic review, meta-analysis, or other knowledge synthesis review?

Q24 Please use this space to provide any additional comments or thoughts that you have regarding the role of business librarians in supporting knowledge synthesis.

\section{Notes}

1. Maria J. Grant and Andrew Booth, "A Typology of Reviews: An Analysis of 14 Review Types and Associated Methodologies," Health Information and Libraries Journal 26, no. 2 (2009): 91-108, https://doi.org/10.1111/j.14711842.2009.00848.x.

2. Clarivate Analytics, “Web of Science Core Collection” (2020), available online at https://login.webofknowledge.com/ [accessed 26 October 2020].

3. Justin Paul and Alex Rialp Criado, "The Art of Writing Literature Review: What Do We Know and What Do We Need to Know?" International Business Review 29, no. 4 (August 1, 2020): 101717, https://doi.org/10.1016/j. ibusrev.2020.101717; Hannah Snyder, "Literature Review as a Research Methodology: An Overview and Guidelines," Journal of Business Research 104 (November 1, 2019): 333-39, https://doi.org/10.1016/j.jbusres.2019.07.039.

4. CEBMa, "Center for Evidence Based Management," available online at https://cebma.org/ [accessed 26 October 2020].

5. Campbell Collaboration, "The Campbell Collaboration," Campbell Collaboration, available online at https://campbellcollaboration.org/ [accessed 26 October 2020].

6. Campbell Collaboration, "New Campbell Business and Management Coordinating Group," Campbell Collaboration, available online at https://campbellcollaboration.org/news-and-events/news/new-campbellbusiness-and-management-coordinating-group.html [accessed 26 October 2020].

7. Clarivate Analytics, "Web of Science Core Collection" (2020), available online at https://login.webofknowledge.com/ [accessed 26 October 2020].

8. David Moher et al., "Preferred Reporting Items for Systematic Reviews and Meta-Analyses: The PRISMA Statement," PLOS Medicine 6, no. 7 (July 21, 2009): e1000097, https://doi.org/10.1371/journal.pmed.1000097. 
9. Melissa L. Rethlefsen et al., "Librarian Co-authors Correlated with Higher Quality Reported Search Strategies in General Internal Medicine Systematic Reviews," Journal of Clinical Epidemiology 68, no. 6 (June 2015): 617-26, https://doi.org/10.1016/j.jclinepi.2014.11.025; Mikaela Aamodt, Hugo Huurdeman, and Hilde Strømme, "Librarian Co-authored Systematic Reviews Are Associated with Lower Risk of Bias Compared to Systematic Reviews with Acknowledgement of Librarians or No Participation by Librarians," Evidence Based Library and Information Practice 14, no. 4 (December 13, 2019): 103-27, https://doi.org/10.18438/eblip29601.

10. Martha R. Harris, “The Librarian's Roles in the Systematic Review Process: A Case Study," Journal of the Medical Library Association 93, no. 1 (January 2005): 81-87, https://www.ncbi.nlm.nih.gov/pmc/articles/PMC545126/.

11. Holly K. Grossetta Nardini et al., "Librarians as Methodological Peer Reviewers for Systematic Reviews: Results of an Online Survey," Research Integrity and Peer Review 4, no. 1 (November 27, 2019): 23, https://doi. org/10.1186/s41073-019-0083-5.

12. Amy Riegelman and Megan Kocher, "For Your Enrichment: A Model for Developing and Implementing a Systematic Review Service for Disciplines outside of the Health Sciences," Reference and User Services Quarterly 58, no. 1 (October 10, 2018): 22-27, https://doi.org/10.5860/rusq.58.1.6837; Amelia Kallaher et al., "Library Systematic Review Service Supports Evidence-Based Practice outside of Medicine," Journal of Academic Librarianship 46, no. 6 (November 1, 2020): 102222, https://doi.org/10.1016/j.acalib.2020.102222.

13. Susan A. Murphy and Catherine Boden, "Benchmarking Participation of Canadian University Health Sciences Librarians in Systematic Reviews," Journal of the Medical Library Association: JMLA 103, no. 2 (April 2015): 73-78, https://doi.org/10.3163/1536-5050.103.2.003; Lorraine Toews, "Benchmarking Veterinary Librarians' Participation in Systematic Reviews and Scoping Reviews," Journal of the Medical Library Association 107, no. 4 (October 1, 2019): 499-507, https://doi.org/10.5195/jmla.2019.710.

14. Michael B. Harari et al., "Literature Searches in Systematic Reviews and Meta-Analyses: A Review, Evaluation, and Recommendations," Journal of Vocational Behavior 118 (April 1, 2020): 103377, https://doi.org/10.1016/j. jvb.2020.103377.

15. Zahra Premji, "Exploring the Involvement of Librarians in Systematic Reviews in Business" (Ontario Library Association Super Conference, January 2020), available online at https://www.olasuperconference.ca/ wp-content/uploads/2020/01/Premji_OLA2020_BusinessLibrarianInvolvement_StandardPoster.pdf_accessed 26 October 2020].

16. Ryan Splenda, "Systematic Reviews in Business and Management: A New Role for Business Librarians," Ticker: The Academic Business Librarianship Review 4, no. 2 (2020), https://doi.org/10.3998/ticker.16481003.0004.205.

17. Toews, "Benchmarking Veterinary Librarians' Participation in Systematic Reviews and Scoping Reviews."

18. Angela J. Spencer and Jonathan D. Eldredge, "Roles for Librarians in Systematic Reviews: A Scoping Review," Journal of the Medical Library Association: JMLA 106, no. 1 (January 2018): 46-56, https://doi.org/10.5195/ jmla.2018.82.

19. Murphy and Boden, "Benchmarking Participation of Canadian University Health Sciences Librarians in Systematic Reviews."

20. Toews, "Benchmarking Veterinary Librarians' Participation in Systematic Reviews and Scoping Reviews."

21. C.A. Beverley, A. Booth, and P.A. Bath, "The Role of the Information Specialist in the Systematic Review Process: A Health Information Case Study," Health Information and Libraries Journal 20, no. 2 (June 2003): 65-74, https://doi.org/10.1046/j.1471-1842.2003.00411.x.

22. Murphy and Boden, "Benchmarking Participation of Canadian University Health Sciences Librarians in Systematic Reviews."

23. Toews, "Benchmarking Veterinary Librarians' Participation in Systematic Reviews and Scoping Reviews."

24. Krystal Bullers et al., "It Takes Longer than You Think: Librarian Time Spent on Systematic Review Tasks," Journal of the Medical Library Association: JMLA 106, no. 2 (April 2018): 198-207, https://doi.org/10.5195/jmla.2018.323.

25. Bullers et al., "It Takes Longer than You Think."

26. Julian P.T. Higgins et al., "Cochrane Handbook for Systematic Reviews of Interventions, 2nd Edition I Wiley," Wiley.com, 2019, https://www.wiley.com/en-us/Cochrane+Handbook+for+Systematic+Reviews+of+Inte rventions,+2nd+Edition-p-9781119536628; Shannon Kugley et al., "Searching for Studies: A Guide to Information Retrieval for Campbell Systematic Reviews," Campbell Systematic Reviews 13, no. 1 (2017): 1-73, https:/doi. org/10.4073/cmg.2016.1.

27. Murphy and Boden, "Benchmarking Participation of Canadian University Health Sciences Librarians in Systematic Reviews."

28. Toews, "Benchmarking Veterinary Librarians' Participation in Systematic Reviews and Scoping Reviews."

29. Premji, "Exploring the Involvement of Librarians in Systematic Reviews in Business."

30. Robin Desmeules, Sandy Campbell, and Marlene Dorgan, "Acknowledging Librarians' Contributions to Systematic Review Searching," Journal of the Canadian Health Libraries Association / Journal de l'Association Des 
Bibliothèques de La Santé Du Canada 37, no. 2 (August 7, 2016), https://doi.org/10.5596/c16-014.

31. Kallaher et al., "Library Systematic Review Service Supports Evidence-Based Practice Outside of Medicine."

32. Whitney A. Townsend et al., "A Competency Framework for Librarians Involved in Systematic Reviews," Journal of the Medical Library Association : JMLA 105, no. 3 (July 2017): 268-75, https://doi.org/10.5195/jmla.2017.189.

33. Riegelman and Kocher, "For Your Enrichment."

34. Mark Engebretson, "Major Training Grant for Librarians Will Advance Skills," Continuum I University of Minnesota Libraries (blog, September 16, 2020), available online at https://www.continuum.umn.edu/2020/09/ major-training-grant-for-librarians-will-advance-skills/. [accessed 26 October 2020].

35. Murphy and Boden, "Benchmarking Participation of Canadian University Health Sciences Librarians in Systematic Reviews."

36. Toews, "Benchmarking Veterinary Librarians' Participation in Systematic Reviews and Scoping Reviews."

37. Townsend et al., "A Competency Framework for Librarians Involved in Systematic Reviews."

38. Toews, "Benchmarking Veterinary Librarians' Participation in Systematic Reviews and Scoping Reviews."

39. Toews, "Benchmarking Veterinary Librarians' Participation in Systematic Reviews and Scoping Reviews."

40. John P.A. Ioannidis, "The Mass Production of Redundant, Misleading, and Conflicted Systematic Reviews and Meta-Analyses," Milbank Quarterly 94, no. 3 (2016): 485-514, https://doi.org/10.1111/1468-0009.12210.

41. Julian P.T. Higgins et al., "Cochrane Handbook for Systematic Reviews of Interventions, 2nd Edition I Wiley," Wiley.com (2019), https://www.wiley.com/en-us/Cochrane+Handbook+for+Systematic+Reviews+of+Inte rventions,+2nd+Edition-p-9781119536628; Shannon Kugley et al., "Searching for Studies: A Guide to Information Retrieval for Campbell Systematic Reviews," Campbell Systematic Reviews 13, no. 1 (2017): 1-73, https://doi. org/10.4073/cmg.2016.1.

42. Splenda, "Systematic Reviews in Business and Management."

43. Engebretson, "Major Training Grant for Librarians Will Advance Skills." 